\title{
CINE TUNECINO CONTEMPORÁNEO Y PARTICIPACIÓN DE LAS MUJERES EN LA REVOLUCIÓN ÁRABE
}

\section{CONTEMPORARY TUNISIAN CINEMA AND WOMEN'S PARTICIPATION IN THE ARAB REVOLUTION}

Author / Autora:

Alejandra Val Cubero

Grupo de investigación TECMERIN

Universidad Carlos III de Madrid

Madrid, Spain

aval@hum.uc3m.es

http://orcid.org/0000-0001-9335-4999

Submitted / Recibido: 25/03/2021

Accepted / Aceptado: 17/05/2021

To cite this article / Para citar este artículo: Val Cubero, A. (2022). Cine tunecino contemporáneo y participación de las mujeres en la revolución árabe. Feminismo/s, 39, 309-331. https://doi.org/10.14198/ fem.2022.39.12

Licence / Licencia:

This work is licensed under a Creative Commons Attribution 4.0 International.

\section{(c) (1)}

(C) Alejandra Val Cubero

Alejandra VAL CUBERO

\section{Resumen}

La revolución de los jazmines, como se denominó a la revolución árabe en Túnez, se ha llevado a la pantalla desde muy diferentes puntos de vista en los últimos diez años, y ninguna revuelta social anterior ha sido tan mediática tanto dentro como fuera de sus fronteras. Los cineastas de distintas generaciones han recogido el sentimiento de la población tunecina antes, durante y tras los altercados del 17 de diciembre de 2010, en el que el joven Mohamed Bouazizi, vendedor ambulante en la pequeña localidad de Sidi Bouzid, se inmoló tras confiscarle la policía su puesto de frutas, y su muerte desató la revuelta popular en todo el país, y posteriormente en muchos países árabes. Nuestra hipótesis de partida es que el mayor nivel educativo de las mujeres tunecinas, con respecto a otros países de su entorno, el trabajo que desde hace más de cinco décadas han realizado los distintos movimientos de mujeres y asociaciones feministas en Túnez, y el camino emprendido por las directoras pioneras desde los años setenta hasta la actualidad, han sido claves para la contribución activa y comprometida de los directores, pero sobre todo de las directoras de cine, durante este proceso histórico. Directoras y directores 
que han puesto en el centro de sus obras cinematográficas la participación femenina en la política, en tanto que votantes pero sobre todo como candidatas, que han documentado la implicación de las mujeres en la sociedad civil, y no han dudado en filmar a las impulsoras socias y militantes de los distintos movimientos de mujeres para que ellas, en primera persona, narraran los avances, las dificultades, y los retos de la sociedad tunecina contemporánea.

Palabras clave: Túnez; movimientos de mujeres; cine; documentales; largometrajes; revolución de los jazmines.

\begin{abstract}
The Jasmine Revolution, as the Arab revolution in Tunisia was called, has been brought to the screen from many different points of view over the last ten years, and no previous social uprising has been so widely covered by the media both at home and abroad. Filmmakers of different generations have captured the feelings of the Tunisian population before, during and after the riots of 17 December 2010, when the young Mohamed Bouazizi, a street vendor in the small town of Sidi Bouzid, blew himself up after the police confiscated his fruit stall, and his death sparked a popular revolt across the country, and subsequently in many Arab countries. Our starting hypothesis is that the higher educational level of Tunisian women compared to other countries in the region, the work carried out for more than five decades by the various women's movements and feminist associations in Tunisia, and the path taken by pioneering female directors from the 1970s to the present day, have been key to the active and committed contribution of directors, but above all by female directors, during this historical process. Filmmakers who have placed women's participation in politics at the center of their films, both as voters and above all as candidates, who have documented women's involvement in civil society, and who have not hesitated to film the driving forces behind the various women's movements so that they could narrate in the first person, the progress, difficulties and challenges of contemporary Tunisian society.
\end{abstract}

Keywords: Tunisia; women's movements; cinema; documentaries; feature films; Jasmine Revolution.

\title{
1. DOCUMENTALES Y PARTICIPACIÓN DE LAS MUJERES TUNECINAS EN LA POLÍTICA
}

La nueva generación de directoras y directores tunecinos que comenzaron a rodar en los albores del siglo XXI encontraron referentes cinematográficos 
muy importantes en la generación de las pioneras, mujeres nacidas en la década de los cuarenta y cincuenta, que comenzaron a tratar y a filmar las relaciones de género desde una perspectiva muy novedosa en todo el mundo árabe y en el Magreb en particular. Selma Baccar rodó Fatma 75 (1974, 60') a la edad de treinta años, un documental que dio pie a toda una serie de obras de corte feminista (Van Der Peer, 2010). En esta obra, una joven estudiante universitaria intenta escribir un ensayo sobre los derechos de las mujeres en Túnez y para ello aborda varios periodos de la historia del país: el primero de 1930-1938 con la creación de la Unión de mujeres tunecinas; el segundo, de 1939 a 1952, periodo que marcó la relación entre la lucha nacional por la independencia, y la lucha de las mujeres durante esta conflictiva etapa. Finalmente, el periodo posterior a 1956, año en el que Túnez se independiza de Francia (Val, 2021, p.2).

Fatma 75, protagonizada por Jalila Baccar, da la voz a diferentes mujeres de la historia de Túnez, desde Sophonisba, aristócrata cartaginense que luchó contra la invasión de los romanos, a Bouchira Ben Mourad, líder del movimiento de liberación de las mujeres en Túnez y fundadora de la Unión de mujeres islámicas en 1936 (Val, 2021, p. 2). Fatma 75, pese a estar prohibida en Túnez hasta el año 2005 por incluir temas relativos a la educación sexual, los matrimonios mixtos y la herencia, abrió la caja de Pandora a toda una serie de obras donde directoras como Néjia Ben Mabrouk, Kalthoum Bornaz o Moufida Tatli recogieron temas no expuestos por la opinión pública hasta entonces como la violencia contra las mujeres, su participación política y la importancia de la educación femenina ${ }^{1}$.

1. Esta generación de directoras pioneras tunecinas señalaban la falta de referentes cinematográficos, tal y como explica Néjia Ben Mabrouk: «En un principio yo no quería realizar mis propias películas, posiblemente porque me faltaban referentes de directoras. Todos los directores eran hombres, por lo que parecían más natural contar las historias a través de la escritura. Yo quería escribir novelas. En esa época, a finales de los sesenta no había ninguna escuela de cine, ninguna escuela de interpretación, nada que nos pudiera permitir a las jóvenes hacer películas» (Sharif, 1998, p. 204). Néjia Ben Mabrouk rodó el largometraje de corte autobiográfico La Trace (1988) sobre una joven que vive en un pueblo y anhela seguir estudiando, lo que finalmente consigue cuando se marcha de Túnez. Y Moufida Tlatli, en su primer largometraje Les Silences du Palais (1994), hizo referencia a la manera en la que las élites tunecinas vivían sin complejos y en avenencia con los franceses, sometiendo a las clases más pobres, en concreto a las sirvientas que trabajaban en una casa aristocrática tunecina. Kalthoum

Feminismo/s 39, January 2022, 309-331 
Con la llegada del nuevo siglo, los avances de la tecnología (cámaras y equipos de sonido menos pesados, digitalización en el proceso de filmación y de edición) han permitido rodar documentales más económicos y menos intrusivos. Y como señala el especialista en cine del Magreb Kevin Dwyer «la inmolación de Sidi Bouzid no hizo más que acelerar este tren» (2020, p. 234). Por otra parte, la censura y la imposibilidad de criticar la realidad de una manera abierta durante más de sesenta años dieron lugar a que «tras el derrocamiento de Ben Ali surgiera un repunte de este género» (De la TorreEspinosa, 2014, p. 105).

Los directores de diferentes generaciones, pero principalmente las directoras de cine y la generación más joven, querían contar lo que estaba ocurriendo porque lo consideraban, como así ha sido, de vital importancia para la historia de Túnez y de los países vecinos. Por ello, tras el estallido de la revolución, uno de los temas que más se va a repetir en los documentales realizados a partir de 2011 es la reconstrucción política y más específicamente la participación de las mujeres en la formación de partidos políticos. La paridad política, reclamo de los movimientos feministas desde los años ochenta del siglo XX, fue aprobada tras la revolución de los jazmines, y las listas que no fueran paritarias no pudieron presentarse a las primeras elecciones democráticas del país.

El documental Militantes $\left(2012,78^{\prime}\right)$ de la escritora, profesora y cineasta Sonia Chamkhi, nos lleva a un Túnez posrevolucionario en plena transición política ${ }^{2}$. El documental muestra quiénes son las mujeres que por primera vez tras la caída de Ben Ali se presentan como candidatas a la Asamblea Constituyente en las primeras elecciones libres. Sonia Chamkhi entrevista a ocho mujeres muy diversas, de diferentes tendencias ideológicas, pero que comparten varias características: la mayoría nació en los albores de los años cincuenta del siglo XX, y todas han sido mujeres muy comprometidas al participar en asociaciones de mujeres, de derechos humanos o movimientos para la libertad de expresión.

Bornaz, por su parte, abordó el tema de la violencia doméstica en Jugement d'une femme (2003), y el del desigual reparto de la herencia en l'Autre Moitié du ciel (2008).

2. Sonia Chamkhi fue nombrada Directora General del Centro Nacional de Cine y de Imagen (CNIC) en enero de 2020. 
En el documental aparece la abogada Bochra Beljaj Hmida, cofundadora de la Asociación Tunecina de Mujeres Demócratas en 1989, diputada de la Asamblea de Túnez en 2014 y miembro del comité ejecutivo del movimiento Nidaa Tounes desde el 2012 3 . Bochra Beljaj Hmida fue la abogada de un caso muy controvertido que ocupó la primera página de todos los medios de comunicación en el año 2012, al defender a una joven violada por tres policías, joven que fue acusada de atentado contra el pudor y pasó varios meses en prisión. La valentía de la mujer agredida, el apoyo de su familia y las voces que surgieron entre la población civil criticando abiertamente el proceso lograron liberar a la joven y condenaron a prisión a los policías ${ }^{4}$.

En el documental de Sonia Chamkhi también se entrevista a Radhia Nasraoui, abogada, activista y miembro del Partido Comunista de los Obreros Tunecinos, un partido fundado en 1983 y legalizado el 18 de marzo de 2011; y a Sihem Ben Sedrine, periodista y fundadora del Consejo Nacional para las Libertades en Túnez, creado en 1998. Otra de las voces más destacadas del documental es la feminista y abogada Saïda Garrach, que se convertirá en la primera portavoz de la presidencia de la República Tunecina entre 2017-2019. Saïda Garrach entró en política en el año 2011 de la mano del partido político Nidaa Tounes, y ha sido Secretaria General de la Asociación Tunecina de Mujeres Demócratas, al igual que la historiadora Latifa Lakdhar, fundadora de dicha asociación y Ministra de Cultura desde 2015 hasta 2016.

Si Sonia Chamkhi retrata a las políticas y militantes nacidas en los cincuenta y sesenta, la americana Jessie Deeter filmó a las mujeres que pertenecen a una generación más joven, la nacida entre los años ochenta y los noventa del siglo XX. A Revolution in Four Seasons $(2016,86$ ') comienza con las imágenes grabadas por un aficionado durante la inmolación de Mohammed Bouazizi, imágenes que vienen acompañadas de la canción del General - nombre artístico del cantante Hamada Ben Amor-y su Rais Lebled, que se convirtió en uno de los himnos nacionales de la revolución tunecina.

3. La abogada defendió a la directora de cine Nadia El Fani por las amenazas sufridas por el documental Laïcité, Inch'Allah! (2010) sobre la laicidad en Túnez.

4. La historia fue llevada al cine por la directora Kaouther Ben Hania en la película $L a$ Belle et la Meute (2018). 
En su letra, el rapero protesta contra la corrupción del entonces presidente Ben Ali destacando la falta de esperanza de una juventud empobrecida ${ }^{5}$.

La directora siguió durante cuatro años los pasos de dos jóvenes mujeres: la bloguera y periodista Emma Ben Jemaa, que aboga por una Túnez democrática y laica; y la política conservadora Jawhara Ettis, perteneciente al partido islamista Ennahda y elegida por la Asamblea Constituyente para debatir y redactar una nueva Constitución. Ambas representan dos maneras de pensar y de vivir: Emma se declara atea, al contrario que Jawhara, para quien la religión musulmana es fundamental en la definición del nuevo Túnez. Ambas son mujeres jóvenes con mucha determinación, y que quieren lo mejor para las nuevas generaciones. Tanto Emma como Jawhara proceden de clases sociales distintas, más cosmopolita en el caso de la primera y de procedencia rural en el caso de la segunda, aunque las dos se manejan sin problemas en árabe, francés e inglés, idioma este último en el que está rodado el documental.

Durante el rodaje, que duró cuatro años, las dos protagonistas contraen matrimonio, tienen descendencia y deben compaginar su papel público con la maternidad. En el caso de la periodista, aparecen muy claras sus dificultades para compaginar la vida familiar con la participación pública porque su pareja no está muy presente -al implicarse también en un partido político de corte progresista-. En el caso de la familia de Jawhara, y pese a las críticas de muchos miembros de su comunidad, hay varias escenas que muestran la entrega de la joven: durante un pleno en la Asamblea en la que se están debatiendo diferentes leyes, es consciente de la fragilidad del proceso democrático y como ella señala: «yo pienso en el futuro, aunque me pierda cosas en el presente», en clara alusión a los primeros meses de su hija, y en la escena final junto a su marido, éste menciona que «su mujer ha estado donde tenía que estar».

El documental está estructurado en cuatro partes: El verano de la esperanza (2011), al ser ese año cuando tuvieron lugar las primeras elecciones democráticas y la alegría era patente en las ciudadanas y ciudadanos que

5. Túnez se ha convertido en la capital del Hip Hop árabe con raperos muy críticos con el poder entre los que se encuentran Hamzaoui Med Amine, Armada Bizerta, Weld El 15 o Klay BBJ (Zegnani, 2020). 
por primera vez iba a votar. El otoño del trabajo (2012) por las complejas negociaciones que tuvieron lugar hasta aprobar la nueva Constitución tras la caída del dictador. El invierno de la desesperación (2013), en la que fueron asesinados los políticos Chokri Belaid y Mohamed Brahmi. Y finalmente La primavera de la democracia (2014), al celebrarse el 26 de octubre de ese mismo año las segundas elecciones nacionales.

La participación de las mujeres en las primeras elecciones democráticas en la historia de Túnez también está muy bien recogida en Tunisie, année zéro (2011, 52'). La historiadora y documentalista Feriel Ben Mahmoud narra los entresijos políticos en torno a las primeras elecciones presidenciales en enero de 2011, elecciones muy complejas porque se presentaron ciento diez partidos políticos. El documental se inicia en el momento preciso en que los tunecinos van a votar: las largas colas y la esperanza del cambio se siente en la calle y ante la cámara se dan cita personas anónimas que esperan, porque es la primera vez que acuden a las urnas. Un flashback nos traslada al inicio de la campaña política, en la que los diferentes partidos políticos comenzaron a formarse y a establecer su agenda política; y en donde el espectador es consciente del peso cada vez mayor del partido islamista Ennahda y sus estrategias para atraer a la población tunecina. La directora siguió a distintos líderes, grabó mítines y debates políticos para mostrar el abanico de posturas ideológicas; mientras que para los más conservadores como Ennahda el peso de la religión musulmana era clave, otros partidos de tendencia más progresistas como el Foro Democrático para el Trabajo y las Libertades y el Partido Progresista Demócrata destacaban la importancia de un Túnez laico. Feriel Ben Mahmoud siempre otorga en sus documentales un papel protagonista a las historias de las mujeres y en este caso concreto se pregunta qué es lo que pudo llevar al partido Ennahda a conseguir ochenta y nueve puestos de los doscientos diecisiete de la Asamblea Constitucional, votos que dieron la victoria al partido fundamentalista musulmán.

El papel que la religión musulmana ocupaba y ocupa en la esfera pública sigue siendo uno de los temas más debatidos antes y después de la revolución de los jazmines. Nadia El Fani rodó Ni dieu ni maître en el año 2010, documental que más tarde se llamaría Laïcité, Inch'Allah! El documental, que se desarrolla en tres partes durante el mes de Ramadán, aboga claramente por una Túnez laica. Nadia El Fani, muy comprometida con los derechos 
humanos y en especial con los derechos de las mujeres, se apoya en el primer artículo de la constitución tunecina para rebatirlo: «Túnez es un Estado libre, independiente y soberano; su religión es el Islam, su lengua es el árabe, y su régimen, la República» ${ }^{6}$. El documental Laïcité, Inch'Allah ! le llevó a sufrir numerosas amenazas, boicot en las salas donde se proyectaba y tuvo que hacer frente a varias denuncias. Su abogada fue Bochra Belhaj Hmida, miembro de la Asociación Tunecina de Mujeres Democráticas y protagonista de varios documentales realizados tras la revolución de los jazmínes ${ }^{7}$. Nadia El Fani rodó el documental junto a Caroline Fourest Elles livrent bataille: Nos seins, nos armes $(2013,68$ ') sobre el movimiento feminista Femen, nacido en el año 2008 en Ucrania. Y años más tarde Mezni Hafaiedh rodaría Au-delà de l'ombre (2017), sobre la libertad sexual y los derechos LGTB en Túnez, cuya principal protagonista es la activista de Femen, Amina Sboui.

El último documental hasta la fecha sobre la participación de las mujeres en la política tunecina ha sido She had a dream (2020, 90') de Raja Amari. La directora siguió a Ghofrane Binous, joven que se presentó a las elecciones legislativas de Túnez en 2019 para sacar a la luz pública aspectos relativos a la raza y la discriminación que sufren las personas de color. El título del documental hace referencia al discurso de Martin Luther King I have a dream, discurso pronunciado en 1963 en las escalinatas del monumento de Lincoln, en el que habló de un futuro en el cual la gente de tez negra y blanca pudiesen coexistir armoniosamente y como iguales.

6. «La Tunisie est un État libre, indépendant et souverain ; sa religion est l'Islam, sa langue est l'Arabe et son régime, la République» (Traducción de la autora).

7. En el año 2003 el tema de la secularización entró de lleno en el debate público. Diferentes partidos políticos como Ennahda, el Foro Democrático para el Trabajo y las Libertades, el Partido Demócrata Progresista y el Congreso por la República firmaron un documento que garantizaba la libertad de creencias para todos los tunecinos y la igualdad entre mujeres y hombres, pero el documento no tuvo ninguna validez por el poder cada vez mayor de los movimientos islamistas y salafistas. Bochra Belhaj Hmida también es una de las protagonistas del documental Militantes (2012) de Sonia Chamkhi. 


\section{DOCUMENTALES Y MOVIMIENTOS DE MUJERES EN TÚNEZ}

La primera asociación de mujeres tuvo sus raíces a principios de los años treinta del siglo XX, con el nacimiento de la Unión de mujeres musulmanas de Túnez en 1936 (Labidi, 2007)8 ${ }^{8}$, y en los cuarenta la Unión de mujeres de Túnez y de orientación comunista vio la luz en $1944^{9}$. A partir de ese momento surgieron otras asociaciones como la Unión nacional de mujeres en Túnez en 1956, con el objetivo de consolidar la integración de la mujer en la sociedad (Labidi, 2009). Las victorias conseguidas por estas asociaciones de mujeres y por otras que surgieron a partir de los ochenta y noventa han sido numerosas: El Código de Estatus Personal de 1956 prohibió la poligamia, aprobó el divorcio, el derecho al voto, los salarios paritarios, la obligatoriedad de los colegios mixtos, y el derecho de las mujeres a trabajar, viajar y gestionar su dinero (Labidi, 2007, p. 21). Y a partir de 1987 se creó un fondo para los hijos y las mujeres divorciadas, se aprobaron diferentes tipos de contrato matrimoniales y los hijos de madre tunecina y padre no tunecino pudieron optar a la nacionalidad de la madre. Las asociaciones de mujeres que fueron claves para promover la educación, la participación de las mujeres en la vida política, así como la emancipación femenina no dudaron en salir a la calle a manifestarse cuando vieron que sus derechos peligraban.

La nueva Constitución, aprobada el 27 de enero de 2013, acuerda en su artículo 46 que «el Estado se compromete a proteger los derechos adquiridos de la mujer. El Estado garantizará la igualdad de oportunidades para mujeres y hombres en lo que respecta al acceso a todas las responsabilidades y en todos los ámbitos. El Estado trabajará para lograr la paridad entre mujeres y hombres en las asambleas elegidas. El Estado tomará las medidas necesarias para eliminar la violencia contra la mujer» (Institut National de la

8. Bchira Ben Mrad dirigió esta asociación hasta 1956. En el desarrollo de la asociación tuvieron mucha importancia las revistas Chems al-Islam (Le Soleil de l'islam) y Leila, considerada una de las primeras revistas feministas tunecinas en lengua francesa.

9. En los años cuarenta, las mujeres tunecinas organizadas en diferentes movimientos, comienzan su lucha contra el colonialismo y empiezan a visitar ciudades y pueblos para convencer a las mujeres y hombres sobre los aspectos negativos del colonialismo. Las primeras integrantes de la Unión de mujeres en Túnez fueron Charlotte Joulain, Hafidha Darrage, Mongia Mouldi, Fatma Ben Romdhane, Fatma Mazigh, Khiari, Kmar El Bahri, Saïda Ben Mohamed, Boujemâa, Azzouz y Ben Abdennebi. 
Statistique, 2015). Sin embargo, antes de su aprobación final, el borrador del artículo 28 de la Constitución levantó un gran debate porque señalaba que la mujer era complementaria el hombre, mientras que en la Constitución de 1956 aparecía el término igualdad entre los sexos. Tras conocerse el borrador, numerosas asociaciones de mujeres como la Asociación Tunecina de Mujeres Demócratas, la Asociación de Mujeres Tunecinas por la Investigación y el Desarrollo y La Liga Tunecina de los Derechos Humanos, entre otros colectivos, firmaron un manifiesto que se hizo público el 2 de agosto de 2012 en el que se abogaba por el término igualdad y no complementariedad ${ }^{10}$. Este comunicado fue presentado por la directora, feminista y diputada Selma Baccar, una de las pioneras del cine en Túnez (Djait, 2013) ${ }^{11}$.

Otro tema, recogido y tratado tras el estallido de la revolución de los jazmines, ha sido los documentales que abordan el papel de los movimientos de mujeres en Túnez y su importancia en la consecución de una sociedad más justa. Este es el caso del documental de la historiadora Feriel Ben Mahmoud, Tunisiennes, sur la ligne de front $(2014,52$ ') quien destaca el peso de las asociaciones de mujeres que lucharon por la abolición de la poligamia, la instauración del divorcio, y la legalización del aborto. La directora interrogó durante dos años a mujeres que fundaron y participaron en estos movimientos, así como a obreras, artistas, militantes, viudas de opositores políticos ... mujeres, todas ellas, que no están dispuestas a que sus derechos y los de toda la sociedad desaparezcan tras tantos años de lucha. El papel de dichos movimientos de mujeres lo desarrolla de una manera más personal e íntima el director Mounir Baaziz en Une vie en dents de scie (2012, 52') sobre la activista y profesora de matemáticas Halima Jouini, quien desde muy joven participó en los movimientos estudiantiles en contra del régimen, en grupos sindicales, en la Asociación Tunecina de Mujeres Demócratas y fue represaliada y encarcelada por sus ideas políticas.

De nuevo, Feriel Ben Mahmoud en Révolution des femmes, un siècle de féminisme arabe $(2014,52$ ') sitúa el presente viajando al pasado, a los años

10. Ambas asociaciones de mujeres se fundaron en 1989. La Liga Tunecina de los Derechos Humanos se creó en 1976.

11. Selma Baccar es diputada de Vía Democrática y Social, partido creado en abril de 2012 como fusión del movimiento Ettajdid y el partido de trabajo tunecino. 
cincuenta, en los albores de la independencia de muchos países árabes, cuando la libertad y la emancipación femenina estaban en la agenda política de los futuros dirigentes desde Abdel Nasser en Egipto a Habib Bourguiba en Túnez, y destaca cómo los nuevos regímenes acabaron defendiendo los valores del patriarcado (Val, 2021, p. 6). Feriel Ben Mahmoud toma imágenes de archivo que se completan con entrevistas a abogadas, políticas, artistas e historiadoras y llega a la conclusión de que en los últimos veinte años muchos han sido los logros y aún más los retos pendientes entre los que se encuentran el avance de los movimientos fundamentalistas de corte religioso que son contrarios a la liberalización de las mujeres.

Estos documentales revalorizan el papel de las mujeres en la historia de Túnez y ponen de relieve, en un momento de gran explosión de los partidos fundamentalistas islamistas y salafistas, que los derechos de las mujeres hubo que pelearlos y defenderlos en la escena pública. Movimientos de mujeres que nacieron en los años treinta del siglo XIX y tomaron amplitud en los ochenta y noventa, justo cuando el entonces primer ministro Ben Ali en un golpe de Estado se hizo con el poder en 1987 y asumió la presidencia. Su gobierno, interesado en mantener las buenas relaciones con Occidente, continuó con las políticas de igualdad, pero vigiló muy de cerca las asociaciones de mujeres, consideradas como una amenaza, y muchas activistas tuvieron penas de cárcel, fueron torturadas o se exiliaron, como fue el caso de Naziha Réjiba, fundadora del Consejo Nacional para las libertades en Túnez en 1998, o la abogada Radhia Nasraoui, confundadora de la Asociación contra la tortura en Túnez ${ }^{12}$.

Durante los mandatos presidenciales de Habib Bourguiba (1957-1987) y de Ben Ali (1987-2011) las organizaciones de mujeres de Túnez estuvieron siempre bajo las políticas patriarcales del régimen (Gilman, 2007, p. 98); sin embargo tras la caída de Ben Ali, no sólo se multiplicó el número de asociaciones de mujeres, sino también se derribó el muro que impedía hablar, y las obras cinematográficas recogieron las ansias de los tunecinos

12. La feminista y abogada fundó la asociación Verdad y Libertad en 2014 con el objetivo de determinar las violaciones graves cometidas durante la dictadura de Ben Ali y compensar a las víctimas. 
y tunecinas de expresarse en las calles, en las redes sociales, en la música, en la prensa, y en los libros.

\section{DOCUMENTALES Y SOCIEDAD CIVIL}

Los documentales tunecinos contemporáneos realizados tras la revolución de los jazmines también nos han contado la violencia, las amenazas, las torturas sufridas antes y después de la caída de Ben Ali; y las dificultades de expresarse públicamente debido a la censura. Dorra Bouzid, une tunisienne, un combat $(2012,54)$ de Walid Tayaa recoge la vida, las relaciones y las luchas de la feminista y periodista nacida en 1933 en el sureste de Túnez, documental que se convierte en un referente para las generaciones más jóvenes. Dorra Bouzid estudió farmacia en Francia y comenzó a escribir en el periódico nacional L'Action sobre los problemas de las mujeres en Túnez, abogando por la educación femenina y por un código de familia más igualitario, periódico que luego se convertiría en Jeune Afrique. Dorra Bouzid ha colaborado en numerosas revistas feministas, entre ellas Faiza. En el documental cobra especial relevancia el papel de su madre, mujer de ideas liberales que trabajaba como maestra, se desplazaba en bicicleta y se convirtió en un modelo para la activista.

Y Mourad Ben Cheikh en Plus Jamais Peur (2011, 72') entrevistó a personas que habían sido muy críticas con el gobierno, como el periodista Karem Cherif, la joven bloguera Lina Ben Mhenni, que desafió al gobierno con sus ácidos comentarios en las redes, o la abogada y firme defensora de los derechos humanos Radhia Nasraoui. Todos ellos compartían el miedo y la angustia cuando fueron detenidos, a veces torturados. Miedo que ya no quieren sentir más.

En este documental, presentado en el festival de Cannes ese mismo año, Mourad Ben Cheikh describe con precisión los mecanismos de poder utilizados por Ben Ali: prisión de opositores sin juicios ni posible defensa, corrupción política, la avenencia de la policía y el poder ... al tiempo que muestra a un pueblo, el tunecino, cansado de tantos atropellos y donde se destaca el uso que los jóvenes hicieron de internet y de las redes sociales como armas de acción y denuncia. 
El documental finaliza con la frase Ne jamais peur y está dedicado a «todos los que han luchado y no han podido vivir este día», e intercala videos de aficionados que filmaron las protestas, con las últimas imágenes de Ben Ali en la televisión, el 13 de enero de 2011, imágenes repetidas en muchos de los documentales sobre la Primavera Árabe, donde las palabras del dictador que repite «Yo os entiendo, yo os entiendo, yo os entiendo» suenan ahora vacías de sentido ${ }^{13}$.

La joven bloguera, periodista, activista y fotógrafa Lina Ben Mhenni vuelve a aparecer en el documental Tunisia Clash! $(2015,65$ ') de la franco tunecina Hind Meddeb, arrestada dos años antes de filmar esta obra por apoyar al controvertido rapero Weld El $15^{14}$. En Tunisia Clash! la directora recorre el país junto a los raperos Phenix y Weld El 15 y entrevista a otros artistas como Emino, Madou MC, Klay Bbj, la mayoría habían sufrido terribles represiones: conciertos boicoteados, vigilancia policial, prisión, tortura ... El nombre del Clash procede de la cultura del Hip Hop. Clash es la confrontación de dos cantantes que se retan con sus ingeniosas estrofas. Clash también significa ruptura, separación y escisión.

Las voces de mujeres de diferentes clases sociales, económicas y culturales están muy bien representadas en los documentales Rouge Parole (2012, 94') y en Lost in Tunisia (2016, 65') del realizador Elyes Baccar. Rouge Parole también se inicia con el último discurso televisivo de Ben Ali junto con las imágenes de un cementerio, aludiendo a los miles de fallecidos antes del estallido de la revolución. Elyes Baccar con cámara al hombro grabó distintas manifestaciones de policías, de periodistas, de artistas y presenta una Túnez con muchas ganas de hablar y que de hecho habla: en las librerías salen a la venta los libros anteriormente censurados, en las calles los jóvenes cantan: «Lárgate! ${ }^{15}$ y en las paredes de los edificios los grafitis repiten los mismos

13. «Je vous comprend, Je vous comprend, Je vous comprend» (Traducción de la autora). 14. Lina Ben Mhenni murió en el año 2020 a los treinta y seis años de edad. La joven activista hizo de la mujer tunecina y sus derechos el centro de su lucha política. Se hizo conocida por su blog Una chica tunecina, escrito en inglés, francés y árabe. La activista apareció en numerosas obras como Génération Maudite (2013, 60') de Nasreddine Ben Maati, documental que indaga sobre el papel del ciberactivismo antes y durante la Revolución (Rubio, 2020).

15. La palabra Degagé! o Lárgate! daría título a otro documental rodado por Mohamed Zran en el año 2012 y en el que los niños tuvieron especial protagonismo. 
eslóganes: «Túnez es libre; El pueblo ha liberado a la policía y dice no a la dictadura o Ben Ali, la policía te escupe encima», tanto en árabe como en francés ${ }^{16}$.

Una sociedad a quien se le ha retirado la palabra durante décadas y «debe aprender a hablar» como señala una periodista, y otro compañero responde: «ahora es la explosión de la palabra». Mientras en otra escena, rodada en un café popular, un anciano asiente: «el pan viene antes que la libertad», mientras que su compañero y jugador de dominó replica: «no, la libertad viene antes que el pan». En las últimas imágenes del documental vemos las manifestaciones que están teniendo lugar en el mismo momento en Egipto y en Libia y el apoyo de los tunecinos a los ciudadanos de estos países.

En Lost in Tunisia, Elyes Baccar interpela a su madre que «él quiere hacer un documental sobre la mujer tunecina pero no sabe por dónde empezar», a lo que su madre responde: «siempre has amado a las mujeres», insinuando que no le será difícil encontrar el tono con el que rodar. El director recorrió el país, de la capital a Kef, Ain Draham, Tataouine, para observar y escuchar la voz de esposas, estudiantes, ancianas, campesinas o desempleadas. El resultado final es una obra que no habla sólo sobre las mujeres tunecinas, sino sobre la diversidad del pueblo tunecino y de sus diferentes condiciones sociales y económicas.

La implicación directa de las directoras y directores en el cambio democrático de Túnez se hace más introspectivo en el último documental de la activista y realizadora Fatma Chérif y su proyecto Il neige à Sidi Bon Said, que se encuentra en estos momentos en post-producción, gracias al programa de ayudas de la Doha Film Institution. Las continuas preguntas de sus hijos ante los viajes de la realizadora entre París y Túnez le llevan a Fatma Chérif a explicar el cambio político acontecido en Túnez en los últimos veinte años, mezclando recuerdos del pasado, fotos de su familia, imágenes de archivo y reflexiones personales.

16. «La Tunisie est libre; Le peuple a libéré la police et dit non à la dictature o Ben Ali, la police te crache dessus» (Traducción de la autora). 


\section{LARGOMETRAJES DE FICCIÓN, MUJERES Y EMANCIPACIÓN}

El cine tunecino realizado tras la revolución de los jazmines ha ganado numerosos premios en festivales internacionales: Millefeuille de Nouri Bouzid obtuvo el premio al mejor director árabe en el Festival de Abu Dhabi en 2012; À peine j'ouvre les yeux de Leyla Bouzid, el premio del público en la Mostra de Venecia en 2015; Hedi, un vent de liberté, de Mohamed ben Attia, premio a la mejor película y mejor actor en el festival de Berlín 2016; La Belle et la meute, de Kaouther ben Hania, premio de la mejor creación sonora en el Festival de Cannes de 2017; Noura rêve (2019) de Hinde Boujemaa, seleccionada en el Festival de San Sebastián y en Toronto; Un fils (2019) de Mehdi Barsaou, premio al mejor actor y premio Interfilm en la Muestra de Venecia en ese mismo año.

La mayoría de estas películas abordan el tema de la libertad, la emancipación femenina y los problemas de la juventud, en un país donde de los once millones de habitantes, la mitad de la población tiene menos de treinta años (Institute National de Statistique, 2019). Millefeuille (2012) de Nouri Bouzid, con la participación de Lotfi Abdelli y Fathi Messelmani, describe el tema de la revolución tanto a nivel individual como social. La historia transcurre en Túnez en enero de 2011. Zaineb y Aicha, dos primas que trabajan en una cafetería, la primera como camarera y la segunda como cocinera, reciben la visita de sus futuros esposos. El novio de Zaineb reside en Francia y quiere casarse con la joven, pero desea que esta lleve velo. Por su parte, Aicha, profundamente creyente, está enamorada de Hamza, un joven islamista radical recién salido de prisión. De una manera o de otra ambas luchan contra la visión conservadora de su entorno y encuentran, no sin dolor, su camino. Nouri Bouzid vuelve a tratar en su última película Les Épouvantails (2019) el tema de la solidaridad femenina. Las jóvenes Zina y Joe regresan a Túnez desde Siria, donde habían sido secuestradas, violadas y torturadas. Una ha perdido a su hijo recién nacido, otra está embarazada y la ayuda de la abogada Nadia y de la doctora Dora es vital en un ambiente que las desprecia y las margina ${ }^{17}$.

17. Nouri Bouzid ha abordado las relaciones de género en la mayor parte de sus largometrajes. En Bezness (1992) trató la prostitución y las relaciones de sororidad en Bent Familia (1997) o Poupées d'Argile (2002). También ha escrito los guiones de películas

Feminismo/s 39, January 2022, 309-331 
Elyes Baccar, quien rodó dos documentales al inicio de la revolución de los jazmines, relata en Tunis by Night (2017) el incipiente estallido de la primavera árabe de la mano de una familia muy diversa: la hija es una joven apasionada del teatro y del baile que canta en un grupo alternativo de rock, el hermano y la madre tienen fuertes ideas religiosas y son muy conservadores; y el padre, un periodista de ideas liberales que dirige un programa de radio desde hace dos décadas y debe decidir, en el último programa antes de jubilarse, si informa sobre el incidente ocurrido en la ciudad de Sid Bouzi y la inmolación del joven vendedor, o no tomar parte.

La juventud y su deseo de cambio está muy bien reflejada en la ópera prima de Leyla Bouzid, Á peine j'ouvre les yeux (2015). Bouzid, nacida en Túnez en 1984 y educada en la prestigiosa escuela francesa de cine La Fémis, sitúa su obra en el verano de 2010, un año antes de la revolución. Aparece un Túnez dinámico, culturalmente muy activo y en el que también se aprecia el peso de la dictadura y de la represión: Farah Kallel estudia su examen para entrar en la escuela de medicina mientras ensaya y da conciertos en un grupo de rock abiertamente opuesto al régimen, y por estas razones es apresada y torturada en prisión. En la película se tratan muchos temas sociales y también políticos: desde una madre y una abuela protectoras que instan a que su hija se concentre en los estudios de medicina y abandone la música, hasta un padre más permisivo que vive en Gazfsa y trabaja en una mina de fosfato, uno de los lugares donde prendió la mecha de la revolución ${ }^{18}$. La música, como en la mayoría de los documentales y películas que abordan la Primavera Árabe, es una parte fundamental en la narración y en la vida de los jóvenes que piden cambios. En esta película la banda sonora fue compuesta

muy importantes para el tema abordado en este artículo, desde Les Silences du Palais (1994) y La Saison des Hommes (2000) junto a Moufida Tlatli; hasta la exitosa Un été à la Goulette (1996) con Férid Boughedir, entre otras muchas obras.

18. La cuenca minera de Gafsa, en el centro oeste de Túnez y frontera con Argelia, tiene verdadero protagonismo en el documental Maudit soit le phosphate $(2012,85$ ') de Sami Tlili. El joven director planteó, como más tarde hicieron otros muchos documentales y estudios académicos, que la verdadera revolución comenzó en el año 2008 en esta área, donde las manifestaciones de los trabajadores, a causa de las duras condiciones de vida, fueron brutalmente reprimidas. 
por el compositor británico-sirio Khyam Allami, quien mezcló canciones tradicionales tunecinas en árabe con melodías de rock ${ }^{19}$.

Túnez tiene la Constitución más progresista del mundo árabe. El artículo 46, aprobado en enero de 2014, no sólo garantiza la igualdad de oportunidades entre mujeres y hombres en todos los campos, sino que la Ley Orgánica 58/2017 del 11 de agosto suprime el controvertido artículo 227 bis del Código Penal que permitía a un violador de una menor evitar pena de cárcel si se casaba con ella. La ley incluye la cárcel para los violadores y el delito de acoso sexual, y fue una ley muy peleada por diferentes asociaciones feministas tunecinas. La nueva ley contempla también el delito de acoso sexual incluido el verbal, para el que se disponen multas de unos 1.000 dinares (unos 350 euros), y la edad de madurez sexual ha pasado de los trece años a los dieciocho (Fill, 2019).

Unos meses antes de la aprobación de esta ley, la polémica y premiadísima La Belle et la Meute (2017), de la directora Kaouther Ben Hania, se estrenaba en todas las salas de Túnez y también en el extranjero. Ben Hania ya había tratado los abusos sexuales y el patriarcado de la sociedad tunecina en el documental Le Challat de Tunis (2014, 90'). En su primer largometraje abordó el controvertido tema de la violación a menores y entrevistó a la mujer violada por tres policías. La estudiante fue condenada con pena de cárcel por denunciar los abusos y tener relaciones sexuales fuera del matrimonio. La joven consiguió que los tres policías fueran inculpados y arrestados, marcando un antes y un después en la historia de los derechos sexuales en Túnez $z^{20}$.

El cuerpo femenino ocupó un lugar destacado en el espacio público durante las numerosas manifestaciones que tuvieron lugar antes y después de la huida de Ben Ali. En las manifestaciones se cantaba «mi cuerpo me

19. Leyla Bouzid es hija de Nouri Bouzid. Esta película es un homenaje a los jóvenes tunecinos y a los hombres -como su padre en la ficción y en la vida real- comprometidos en los temas de igualdad.

20. La película se tradujo al español bajo el título La Bella y los perros y se realizó en nueve planos secuencia lo que generó una gran tensión en los espacios de mayor contenido emocional, como la comisaria y los centros médicos a los que acudió para ser tratada y pedir ayuda. En la película no sólo se nos muestra una joven luchadora sino también un compañero y amigo que la acompaña y defiende. 
pertenece, no pertenece a nadie más» $\mathrm{O}$ «no me liberas, yo me cuido sola $»^{21}$, al tiempo que numerosos fueron los grafitis en los edificios y los comentarios en las redes sociales que se hicieron eco de estos eslóganes (Val, 2021, p. 4). El cuerpo femenino, la emancipación y la solidaridad entre mujeres está muy presente en Corps Étranger (2016) de la realizadora Raja Amari. En la película la joven Samia abandona Túnez y en Francia encuentra cobijo en casa de un joven de su pueblo, mientras comienza una relación ambigua con la mujer de la casa en la que encuentra trabajo ${ }^{22}$. Mehdi Ben Attia volvió a presentar el deseo femenino en L'Amour des hommes (2017) donde una joven fotógrafa, que ha perdido recientemente a su marido, fotografía a hombres desconocidos que encuentra en la calle. Sus fotografías con fuerte carácter erótico provocan el rechazo de su familia y queda en suspense si la joven mantiene relaciones sexuales con ellos.

En esta contienda contra los sectores más conservadores y reaccionarios, los directores tunecinos hablan de historias de ciudadanas y ciudadanos que ya no aceptan las reglas socialmente impuestas. A veces mediante obras dramáticas como Un fils (2019) de Mehdi Barsaou, película que transcurre durante los primeros meses del año 2011. En la misma se plantean interesantes temas como las relaciones entre padre e hijo, la infidelidad femenina y la posible condena de una mujer a penas de prisión por dicha infidelidad. Aunque sobre todo la película presenta a unos personajes que dudan, que se cuestionan y que aceptan sus errores. O en Demain dès l'aube (2017) en la que Lotfi Achour retrata a tres jóvenes de diferente clase social y educativa. La película nos traslada al 14 de enero de 2011, noche en la que la armada protegerá finalmente a los manifestantes. Una noche en la que los jóvenes reunidos frente al Ministerio del Interior gritaban «Fuera, Ben Ali»; «Gracias, pero ya es suficiente»; «O nos matan o se van, pero aquí no se negocia $»^{23}$.

21. «Mon corps m'appartient, il n'est le honneur de personne»; «Ne me libère pas, je m'en charge» (Traducción de la autora).

22. El cuerpo y el deseo femenino ya los había recogido Raja Amari en Satin Rouge (2002) en la que una madre viuda de cuarenta años que vive con su hija Salma entra una noche en un cabaret e inicia su periodo de transformación a través del baile y la música.

23. «Dehors, Ben Ali», «Merci, mais c'est suffit», «Soit ils nous tuent, soit ils partent, mais il n'y a pas de négociation ici» (Traducción de la autora).

Feminismo/s 39, January 2022, 309-331 
El guiño cómico también aparece en las películas rodadas tras la revolución de los jazmínes, porque el humor también puede ser subversivo, como es el caso de Un Divan à Tunis de Manele Labidi (2020). En la película, Selma, que reside en Francia, vuelve a Túnez en los días anteriores a la revolución e instala un gabinete psicoanalista en el barrio popular de Ezzahra, consulta donde poco a poco van a acudir diferentes vecinos: desde un Imán que duda de su fe, a una mujer casada con serios problemas familiares, una joven que sueña con marcharse del país ... ya que como señalara la directora en una entrevista: «La revolución ha liberado la palabra, hemos pasado de una dictadura que amordazaba a la gente durante décadas a una sociedad en la que se podía decir casi cualquier cosa» (Pajan, 2020).

\section{A MODO DE CONCLUSIÓN}

Ninguna revuelta social anterior, ni la revolución del pan en 1982, ni los altercados de la zona minera de Gafsa de 2008, fueron filmados y difundidos en los medios de comunicación y las redes sociales como la revolución de los jazmines (Kamoun, 2019, p. 38). La caída de Ben Ali dio lugar a «la revolución de la palabra». Revolución de la que fueron partícipes las políticas, periodistas, artistas, abogadas y mujeres de todo tipo de clase y educación, quienes salieron a las calles a dialogar y manifestarse. Y aunque entre enero y septiembre de 2011 se crearon tantas asociaciones de mujeres como desde 1956 hasta 2010 (Labidi, 2015a), han sido los movimientos de mujeres formados a partir de los setenta y ochenta los que sirvieron de caldo de cultivo para convertir a Túnez en el país más avanzado de la zona en cuanto a derechos sociales.

El cine es un documento histórico y social de primera mano para tomar el pulso a la sociedad en la que los directores se inscriben. En la actualidad el número de directoras en Túnez es cada vez mayor. Sus películas están acaparando numerosos premios nacionales e internacionales, como sucedió en las últimas Jornadas Cinematográficas de Cartago del año 2019, en donde de las doce películas en competición, cinco fueron realizadas por directoras del Magreb, entre ellas Noura rêve de Hinde Boujemaa (2019) que obtuvo el Tanit d'Or, y disecciona con bisturí la complejidad del divorcio en Túnez. La protagonista y madre de tres hijos quiere divorciarse, pero su marido preso 
en la cárcel la amenaza por adulterio, pena de hasta cinco años de prisión según recoge el artículo 236 del Código Penal ${ }^{24}$. O L'homme qui a vendu sa peau (2020) de Kaouther Ben Hania, primer largometraje tunecino nominado a los Óscars a la mejor película en lengua no inglesa en el año 2021 y en donde se plantea el complejo asunto de la libre circulación de personas.

Las mujeres tunecinas son las protagonistas de la mayoría de los documentales y largometrajes realizados desde el 2011 y se han convertido, como señala Mario de la Torre Espinosa «en la metáfora de un nuevo Túnez que busca su personalidad nacional, una redefinición que, sin perder su tradición cultural, conlleve la consecución de nuevos derechos en pos de una sociedad absolutamente igualitaria» (2014, p. 116). Desde los inicios de la revolución de los jazmines han pasado más de diez años. El descontento de la sociedad tunecina es palpable en la calle y en las creaciones audiovisuales. Si en la mayoría de los documentales y largometrajes mencionados en este artículo había un halo de optimismo, el sentimiento amargo de que tras la revolución nada ha cambiado se percibe en C'était mieux demain (2012, 71') de la directora belga tunecina Hinde Boujemaa, en la que Aida, una mujer pobre, con hijos y sin hogar asegura que la élite sigue en el poder aunque con diferente nombre, y añade frente a la cámara «que estaría mejor si estuvieran colonizados porque así serían humillados sólo por extranjeros y no por gente de su propio país» ${ }^{25}$. Y en los largometrajes Fatwa (2018) de Mahmoud Ben Mahmoud y Weldi (2018) de Mohamed Ben Attia, se recoge cómo la difícil situación económica, el paro y falta de alternativas lleva a los jóvenes a emigrar de manera ilegal, al tiempo que crecen los partidos fundamentalistas.

La primera elección democrática en Túnez en 2011 fue un jarro de agua fría para las feministas y la oposición secular porque el partido fundamentalista Ennadha se llevó el 41,47\% de los votos y a partir de entonces su ideario ha ido emergiendo y haciéndose más fuerte, al tiempo que se formaban nuevos movimientos de mujeres (Labidi, 2015b). El peso de estos partidos fundamentalistas y salafistas tiene un impacto directo en la situación de las mujeres tunecinas. En 2011 se levantó la prohibición del hijab y cada vez

24. Otras películas premiadas fueron Papicha de Mounia Meddour (Algeria, 2019) y Adam de Mariam Touzani (Marruecos, 2019).

25. El primer largometraje de Hinde Boujemaa es Noura rêve (2019).

Feminismo/s 39, January 2022, 309-331 
son más las mujeres que llevan velo en Túnez, igual que está sucediendo en otros países como Egipto o Argelia ${ }^{26}$.

Los retos pendientes para avanzar en la igualdad son numerosos, desde el desigual reparto de la herencia por razones de género, o la violencia contra las mujeres, hasta la migración y el desempleo juvenil (Labidi, 2015a). Sin embargo, una nueva generación de directoras tunecinas, todas menores de cuarenta años, como Leyla Bouzid, Doria Achour, Hind Meddeb, o Ismahane Lahmar están ahora escribiendo guiones, produciendo y filmando películas y documentales sobre estos y otros asuntos, y muchas de ellas participan en el proyecto «Le cinéma au féminin» para apoyar e impulsar proyectos de cine realizados por mujeres de las clases más desfavorecidas ${ }^{27}$. Solo habrá que esperar un poco para disfrutar de un cine tunecino reflejo de la sociedad que describe, cuestiona y matiza.

\section{REFERENCIAS BIBLIOGRÁFICAS}

Djait, A. (2013, 22 de marzo). Maya Jeribi : Les femmes d'Ennahdha vivent un déchirement réel. DirectInfo. http://directinfo.webmanagercenter.com/2013/03/22/ maya-jeribi-les-femmes-dennahdha-vivent-un-dechirement-reel/

Dwyer, K. (2020). Family Resemblance: An Anthropologist Looks at Moroccan Documentary. En T. Ginsberg y Ch. Lippard (Eds.), Cinema of the Arab World. Contemporary Directions in Theory and Practice (231-278). Palgrave Macmillan. https://doi.org/10.1007/978-3-030-30081-4_8

Fill, A. (2019). Constitución, políticas y Sociedad: derechos de las mujeres en Túnez antes y después de la revolución. Relaciones Internacionales, 42, 175196. https://doi.org/10.15366/relacionesinternacionales2019.42.010

Gilman, S. (2007). Feminist Organizing in Tunisia: Negotiating Transnational Linkages and the State. En Valentine M. Moghadam (Ed.), From Patriarchy to Empowerment: Women's Participation, Movements, and Rights in the Middle East, North Africa, and South Asia (97-119). Syracuse University Press.

26. En 1993 se prohibió que en las fotografías de los documentos oficiales las mujeres se vistieran con hijab. Desde la llegada al poder del partido Ennahda esto es posible.

27. El programa «Le cinéma au féminin» o «El cine en femenino» se fundó en 2019. Las profesoras que participan en este proyecto son todas reconocidas directoras, fotógrafas, montadoras o guionistas tunecinas y está financiado por la Fundación Drosos https://drosos.org/fr/projekte/le-cinema-au-feminin/ 
Institut National de la Statistique (2015). Rapport National Genre Tunisie http:// www.ins.tn/sites/default/files/publication/pdf/rapport\%20national\%20 genre\%20Site\%20_0.pdf

Institute National de Statistique (2019). Annuaire Statistique de la Tunisie 20132017. http://ins.tn/publication/annuaire-statistique-de-la-tunisie-2013-2017

Kamoun, O. (2019). Le cinéma tunisien au lendemain des soulèvements sociaux de 2011. Moyen Orient, 44, 28-44.

Labidi, L. (2007). The nature of transnational alliances in women's associations in the Maghreb: the case of AFTURD and ATFD in Tunisia. Journal of Middle East Women's Studies, 3 (11), 6-34. https://doi.org/10.2979/MEW.2007.3.1.6 Labidi, L. (2009). Condition féminine et réaménagement des sentiments dans le monde arabe. En S. Fatou (Ed.), La recherche féministe francophone. Langue, identités et enjeux (267-278). Karthala. https://doi.org/10.3917/kart. sow.2009.01.0267

Labidi, L. (2015a). Le Printemps arabe en Tunisie : constitutionnalisation des droits des femmes. En J. Baubérot, M. Milot y Ph. Portier (Eds.), Laiicité, Laïcités: Reconfigurations et nouveaux défis: Afrique, Amériques, Europe, Japon, Pays arabes (345-373). Éditions de la Maison des sciences de l'homme. https://doi.org/10.4000/books.editionsmsh.5670

Labidi, L. (2015b). State, institutional and symbolic violence against women: the struggle since the Arab spring and the contribution of Arab women cartoonists. Feminismo/s, 26, 145-174. https://doi.org/10.14198/fem.2015.26.08

Pajan, L. (2020, 23 de junio). Un divan à Tunis: une schizophrénie à la tunisienne. Jeune Afrique. https://www.jeuneafrique.com/mag/892880/culture/ un-divan-a-tunis-une-schizophrenie-a-la-tunisienne/

Rubio Chaves, M. (2020). Una chica tunecina informando sobre la revolución. Lina Ben Mhenni en los documentales (2011-2014). En N. Sánchez-Gey Valenzuela y S. Alés Álvarez. (Eds.), Los Medios de comunicación como agentes de educación social (97-122). Egregius ediciones.

Sharif, V. (1998). History and Cultural Identity of Arab Cinema. Cairo Press.

De la Torre-Espinosa, M. (2014). Políticas de representación en el cine tunecino contemporáneo hecho por mujeres. Espéculo, 53, 105-119.

Val Cubero, A. (2021). De las directoras pioneras tunecinas a la Generación del Jazmín: derechos, cuerpo y resistencia. Comunicación y género, 4 (1), 1-7. https://doi.org/10.5209/cgen.70485 
Van De Peer, S. (2010). Selma Baccar's Fatma 1975: at the crossroads between Third Cinema and New Arab. French Forum. 35, (2/3), 17-35. https://doi. org/10.1353/frf.2010.0013

Zegnani, S. (2020). L'hybridation du rap par les artistes tunisiens: logiques locales et internationales. Ethnographiques.org, 40. https://doi.org/10.25667/ ethnographiques/2020-40/007 